\title{
Research on Reflection and Improvement Strategy of Modern Chinese Teaching in Colleges and Universities
}

\author{
Ying Cao \\ Normal College of Xi'an University,710065
}

\begin{abstract}
Keyword: Colleges and Universities; Modern Chinese; Reflection; Improvement Strategy
\end{abstract}
\begin{abstract}
As a common language of Han people, modern Chinese is widely used. With the continuous development of economy and society in our country, Chinese is gradually going abroad and becoming a worldwide communicative language. The quality of modern Chinese teaching in colleges and universities is directly related to the students' language ability in the future. This article has carried on the research and the reflection to the question existing in the modern Chinese teaching in colleges and university and puts forward some improvement strategies according to his own teaching experience.
\end{abstract}

\section{Introduction}

Modern Chinese is the basic course of Chinese language and literature and is also one of the core courses. Modern Chinese is not only knowledge-rich, but also contains a complex knowledge structure. Learning modern Chinese is an important way to grasp Chinese history and culture, which plays an irreplaceable role in improving the overall quality of the entire nation and the quality of humanities and social sciences. Therefore, to learn modern Chinese well is very important. However, the teaching problems of modern Chinese is an indisputable fact.

\section{Contradictions and Difficulties}

The 21 st century is an information age. In the background of informatization, the exchange, acquisition, storage and transmission of information are particular importance in all fields. Language and script are important carriers of information. Therefore, in a certain sense, the modern Chinese language with the main research object of language and script should become a subject loved and read by the majority of young people. The newly issued teaching reform program of colleges and universities by the Ministry of Education has expanded the course of linguistics and aims to make the teaching of linguistics courses in higher institutions of our country keep pace with the development of the times.

However, what is troubling is that people especially the vast majority of young students under modern life philosophy immerse themselves in the social and information convenience brought by linguistics, while show unique indifference to linguistics. In the social survey, many young students actually do not know the related disciplines such as linguistics. As for the value and significance of learning linguistics is far from possible. The author had talked with a lot of high school teachers and knew that Chinese courses have been weakened gradually. For this kind of situation, the author has a deep confusion that middle school students really can learn modern Chinese by themselves or be innate talent for modern Chinese. In college courses, modern Chinese embodies the characteristics of neither good teaching nor good study. Teachers teach quite laborious but students can not afford to mention much interest, which pays a full proportion of imbalance of teaching effectiveness and hard work of the majority of teachers. Students generally reflect that modern Chinese curriculum has little effect on learning and they do not feel any significant improvement.

In fact, this crisis of teaching and learning was put forward in the 1990s. However, all sectors of society reacted differently. Some people think that language has inherent characteristics. As long as it does not affect the normal communication in future, it is not necessary to learn and no need to worry about. However, many teachers engaged in modern Chinese teaching are deeply disturbed by this situation. Many people of insight have carried out in-depth investigations and serious thinking 
on this phenomenon. They put forward their own opinions and proposals in terms of modern Chinese teachers' literacy, compilation of teaching materials and content updates. Objectively speaking, there are many reasons for the current situation, both teachers and students, macro and micro. The emergence of modern Chinese teaching needs a long-term process. Under the conditions of the Internet, the use of modern Chinese is more and more arbitrary and there is a tendency of gradual spread from individuals to society. For example, idioms are arbitrarily altered by news and advertising media. Under the guidance of commercialization, they are only seeking unconventional ideas and striving to attract people's attention. Many of the moderators also believe in the letter and set a bad example for the majority of young people. Wang Meng, a famous writer in our country, once pointed out that the use of modern Chinese in our country is in disorder at the moment. If this trend is allowed to develop, it will surely affect the humanistic quality of our country's next generation. The haphazard, hazy, vulgar, gamification of the use of modern Chinese has become a popular trend among a large number of young students, which will make China face a profound crisis.

\section{The Importance of Modern Chinese Courses}

The importance of modern Chinese has been mentioned earlier, but the author thinks it is necessary to list it out for single repeat. First of all, the setting of modern Chinese courses has an irreplaceable effect on the promotion of Putonghua. The promotion of mandarin started in the 1950s and has been going on for quite some time. However, why mandarin can not be widely promoted? It can be heard that many people are free to use their own dialect on many occasions. An important reason of this is that they do not know enough about the importance of mandarin. One of the important responsibilities of modern Chinese courses is to put the promotion of Putonghua into practice. Secondly, there are many problems in the use of modern Chinese in the era of information and network. This has brought a huge impact on the norms of modern Chinese. An important mission of modern Chinese education in schools is to regulate and purify the use of modern Chinese and improves students' practical ability of modern Chinese from both theory and practice. Finally, under the wave of globalization, China has gradually moved to the center of the world stage. The standardization of teaching and use of modern Chinese is a prerequisite for the modern Chinese to go global.

We have always been proud of our long history and civilization. Modern Chinese, the core of this value system, plays an irreplaceable role in our daily life and interaction. The importance of modern Chinese was widely ignored may because of its obscurity. The champion of Chinese language contest was taken away by foreign players, while college graduates can not write a decent article. All of these sound absurd and bizarre, but it is actually happening around us. These conditions are enough to arouse the vigilance of the whole society and the education community. Among the current colleges and universities in our country, English is basically a compulsory course, but modern Chinese is not a compulsory course. Why do we not want to learn our own language well? The declining of overall language proficiency of college students is not only a matter of students and schools, but also has a close relationship with social influence.

\section{Problems in Modern Chinese Teaching}

The teaching effect of modern Chinese is not satisfactory at the whole level and many problems are exposed in the teaching process. First of all, the majority of students have a wrong understanding of modern Chinese courses. When it comes to modern Chinese, people unconsciously think that language is born with innate talents. Literacy starts from kindergarten until the beginning of high school. Why people still need to study Chinese in university? It is based on this understanding that many students do not consider it necessary to open a course for modern Chinese. The importance of students not being able to correctly interpret modern Chinese is a major problem in teaching.

Second, although modern Chinese has rich connotations and many concepts, its structure is complex and relatively boring. Teachers can simplify slightly some complicated content in the 
classroom teaching at primary and secondary schools. However, the modern Chinese course in colleges and universities is to reinforce the fragmented knowledge points to become regular things and a lot of difficulties have been increased both in theory and in curriculum design. Many freshmen are also more confused at the beginning why their original learning has suddenly been denied. Differences of teaching methods and content make many students have a fear of emotion.

Third, the teaching method of modern Chinese is relatively old. In the past teaching process, teachers often focus their teaching on the explanation of textbook knowledge and the inculcation of knowledge system. The content of lectures is also limited to teaching materials, ignoring the connection between curriculum and social life. In the era of informatization, this old-fashioned teaching method is lack of new ideas and hard to be accepted by the vast majority of young students. As a result, the classroom atmosphere is dull and boring, students are generally less interested and the enthusiasm and initiative of learning are far from possible. Modern Chinese teaching methods should also make full use of multimedia and other tools to make the course more lively and vivid.

Fourth, the traditional assessment method should be changed. The examination is an important way to test the students' learning outcomes and teachers' teaching effectiveness, which plays an active role in the teaching of modern Chinese. However, the single examination method hinders the healthy development of this course. Colleges and universities should adopt a scientific and flexible approach in the examination of modern Chinese and pay attention to the assessment of students' actual language ability and overall quality. This is not only the requirement of quality education but also a powerful way to improve students' accomplishment in an all-round way.

Fifth, the communication between teachers and students is seldom carried out in modern Chinese teaching, which leads to estrangement between teachers and students and there are very few other aspects of effective communication besides schoolwork. Quality education emphasizes equality and friendliness between teachers and students. Under the prerequisite of respecting teachers, students should dare to question and dare to ask questions. In the classroom, we should enrich the teaching activities and mobilize fully the enthusiasm of students to participate, so that students have a sense of participation, solve fundamentally the students tired of learning, enhance the communication and build a good relationship between teachers and students.

\section{Strategies for Improving Modern Chinese Teaching in Colleges and Universities}

Modern Chinese is the basic course and also the core course of Chinese language and literature professional. In order to break through the shackles of the traditional teaching mode and train more qualified personnel with innovative capabilities, it is imperative that we reform and innovate modern Chinese teaching. In the class lectures, we must constantly update the content of teaching so as to keep up with the trend of the times. In the process of teaching, we should proceed from the students' actual conditions and try our best to make students have a strong interest in modern Chinese. Teaching should be close to reality, so that make students feel they can use what they learn.

Further Clarify the Course Orientation. There are more than one professional orientation in modern Chinese courses, but it sums up no more than two situations. One is to train students in basic theories, knowledge and skills and to cultivate students in understanding, analyzing and using language skills. Second, students should have an understanding of the development of modern Chinese and have certain analytical skills. Modern Chinese is a theoretical and practical course, so that students need to combine effectively the two in order to really learn this course. Many teachers and students are not clear about the orientation of modern Chinese courses. Teachers do not know where to strengthen the education for students and students have no idea what they need to learn. To change this situation, we must start from the fundamental. We position the modern Chinese course as three basic and three abilities. This orientation does not fully reveal the characteristics of modern Chinese courses and it is quite one-sided. Therefore, we should strengthen theoretical research and induction on the orientation of modern Chinese and construct a complete system of modern Chinese knowledge system. 
Arouse Interest and Develop Students' Ability to Use Language Effectively. The aim of modern Chinese teaching is to cultivate students' abilities to understand, analyze and use modern Chinese so that students have the basic ability of language research and improve accomplishment of students' language. Modern Chinese teaching can systematize students' native language and enhance students' consciousness of acting according to the laws of language, so as to lay a solid foundation for them to engage in language work in the future. In student learning, interest is the largest teacher, which requires teachers to study carefully the course materials and improve constantly the content of teaching. In the classroom, teachers should explain some cases with rich sense of the times as much as possible and try to make abstract theoritical things more interesting and specific, so as to mobilize the enthusiasm of students and deepen the understanding of knowledge of students. When explaining the vocabulary, teachers should give more examples to students and let them take the initiative to participate and discuss actively. For example, students are divided into groups to discuss the reasons why the online lexicons appear and the conditions for popularization. Students are allowed to express their opinions and express themselves in class and then teachers should guide and summarize at the end. Another example is different expressions of dialect to say the same thing. Teachers should let students from different regions participate and discuss to deepen the understanding of knowledge.

Emphasis on Cultural Awareness in Teaching. Language is not only a communicative tool, but also a cultural carrier. In modern Chinese teaching, we must pay attention to the excavation of cultural factors. Chinese characters are ideographic characters that have been endowed with rich cultural connotations at the beginning. With the development of society, these cultural connotations have also derived new cultural implications. For example, Jia and Qu these two Chinese characters visually and vividly reflect the ancient marriage inequality between men and women from side aspect. Dual-tone is the trend of Chinese vocabulary development and many monosyllabic words evolved into disyllabic words. Even some polyphonic words and phrases are gradually tightening into disyllabic words. This is closely related to national aesthetic that people like to be uniform and symmetrical beauty. The doctrine of the mean in the Han culture has also been fully reflected in a large number of conjunctions. Therefore, culture plays a very important role in modern Chinese. In teaching, teachers should unify cultural factors into teaching practice so as to make the modern Chinese teaching system more complete.

Change the Traditional Teaching Mode. In classroom teaching, teachers should change the traditional educational philosophy and teaching mode, highlighting the dominant position of students in teaching and learning. Only teachers explain a simple theory to students will let students produce a sense of discontent and they rarely participate. Therefore, students will lose interest gradually in learning. Teachers should correctly guide students from their own reality and analyze their own shortcomings to help them in teaching. With the rapid development of science and technology, students as a group of active thinking are easy to have a great interest in a variety of new things. Teachers should strive to seize this favorable conditions in teaching and combine modern Chinese teaching with reality to make student logically accept knowledge, which not only can stimulate the enthusiasm and initiative of students to learn, but also make students have a deep impression of knowledge in their minds. Besides, teachers should also make efforts to develop students' abilities to analyze and solve language problems so that students can make good use of their knowledge, promote learning and achieve a virtuous circle of learning and using.

\section{Reference}

[1] B. R. Huang and X. D. Liao. Modern Chinese [M]. Beijing: Higher Education Press, 2006.

[2] Y. Q. Guan. Reform Thinking on Modern Chinese Curriculum [J]. Heilongjiang Higher Education Research, 2006 (2).

[3] H. W. Li. Modern Chinese Teaching Reform and Practice of Non-Chinese Major [J]. Modern Science of Education, 2006 (1). 
[4] H. D. Xuan and W. Lu. Many Aspects Combined to Improve the Effectiveness of Modern Chinese Teaching [J]. Journal of Huainan Normal University, 2010.

[5] L. Liu. Reflections on Teaching Reform of Journalism Modern Chinese Course [J]. Journal of Hechi University, 2007 (8).

[6] G. G. Zhou. My View on Modern Chinese Teaching [J]. China University Teaching, 2008 (3).

[7] J. M. Shao. Modern Chinese General Theory [M]. Shanghai Education Press, 2001.

[8] Y. C. Shen and Q. Y. Shen. Discussion on Chinese Teaching Reform in Higher Normal Colleges [J]. Journal of Chongqing Teachers College, 2000 (12).

[9] G. S. Wang. Some Thoughts on Modern Chinese Teaching [J]. Journal of Central China Normal University (Humanities and Social Sciences), 2002 (1).

[10] D. L. Zhao and W. Q. Wang. Chinese Professional Practice Teaching and Innovation Education [J]. Journal of Southwest University for Nationalities, 2005 (5).

[11] H. W. Li. Reform and Practice of Chinese Professional Modern Chinese Teaching [J]. Journal of Changchun University of Science and Technology, 2006 (9).

[12]L. L. Gu. Problems and Countermeasures in Chinese Language and Literature Teaching [J]. Teaching Reform, 2016 (5).

[13] K. K. He. Modern Education Technology [M]. Beijing: Beijing Normal University Press, 2003: 131.

[14] T. Cheng. Some Problems in Teaching Chinese as A Foreign Language [J]. Language Teaching and Research, 1996 (3). 